\title{
One-pot synthesis of a new imidazole-5-carboxylic acid derivative via heterocyclization reaction
}

\begin{abstract}
In the current study, a new benzimidazole molecule 2-(3-bromo-4-hydroxy-5methoxyphenyl)-1-methyl-1H-benzo[d]imidazole-5-carboxylic acid was synthesized via the hetero cyclization of ethyl 4-(methylamino)-3-nitrobenzoate with 5-bromo4-hydroxy-3-methoxybenzaldehyde in the presence of sodium dithionite in DMSO followed by the base hydrolysis. The synthesised compound was characterized using IR, NMR $\left({ }^{1} \mathrm{H}\right.$ and $\left.{ }^{13} \mathrm{C}\right)$ and Mass techniques.
\end{abstract}

Keywords: heterocyclization, benzimidazole, $\mathrm{Na}_{2} \mathrm{~S}_{2} \mathrm{O}_{4}$

\author{
Volume I Issue 4 - 2017
}

Mahima Bhat, Boja Poojary

Department of Studies in Chemistry, Mangalore University, India

Correspondence: Boja Poojary, Department of Studies in Chemistry, Mangalore University, Mangalagangothri, Karnataka, 574 I 99, India, Tel +9|-824-2287262, Fax +9|-824-2287367, Email bojapoojary@gmail.com

Received: August 07, 2017| Published: August 29, 2017
Abbreviations: DMSO, dimethyl sulfoxide; $\mathrm{Na}_{2} \mathrm{~S}_{2} \mathrm{O}_{4}$, sodium dithionite; TMS, tetramethylsilane; $\mathrm{EtOH}$, ethanol; $\mathrm{NaOH}$, sodium hydroxide

\section{Introduction}

From few decades, fused heterocyclic chemistry has occupied a prominent place in Medicinal Chemistry. Moreover, fused imidazole systems have attracted the researcher's interest due to their natural occurrence and significant medicinal applications. ${ }^{1-3}$ Additionally, the benzimidazole derivatives are the bioisosters of natural nucleotides, which can interact easily with the macromolecules (proteins, enzymes and receptors) of the biological system, has made the benzimidazole and its derivatives as the privileged pharmacophore in drug discovery process..$^{4,5}$ They are able to produce anti-inflammatory, ${ }^{6}$ antibacterial, ${ }^{7}$ anti cancer, ${ }^{8}$ analgesic, ${ }^{9}$ antiviral ${ }^{10}$ and anticonvulsant ${ }^{11}$ activitie, etc., Further benzimidazoles also can act as inhibitors for $\alpha$-Glucosidase, ${ }^{12}$ Cyclooxygenase, ${ }^{13}$ Poly (ADP-ribose) polymerase ${ }^{14}$ and lysophosphatidic acid acyltransferase- $\beta .{ }^{15}$ Interestingly, benzimidazoles are also being incorporated into various commercially available drugs. ${ }^{16,17}$ This vast applicability and usefulness of the fused imidazole nucleus inspired us to design and develop the target molecule.

Further, harsh and vigorous reaction conditions as well as tedious work up procedures ${ }^{18,20}$ of the classical methods which are available so far for the synthesis of benzimidazole derivatives necessitate the simple one-pot reductive cyclization method. Furthermore, several new one-pot methods which were reported in recent years utilises either the costly reagents or hazardous reaction conditions. ${ }^{21-23,27}$ Moreover, Sodium dithionite $\left(\mathrm{Na}_{2} \mathrm{~S}_{2} \mathrm{O}_{4}\right)$ a protean reducing agent was able to reduce several functional groups like aldehydes, ketones, conjugated ketones and nitro group. It was also been reported as an agent during one-pot synthesis of the benzimidazole and its derivatives. ${ }^{24-26}$ Thus, advantage of one-pot synthesis to conduct the reaction in more sustainable way by minimizing the use of reagents and solvents as well as with the reduction in reaction time has motivated us to utilize the same in our research.

\section{Results and discussion}

Synthetic strategy for the title compound is as depicted in the
Figure 1. A new benzimidazole derivative (2) was synthesized by reacting ethyl 4-(methylamino)-3-nitrobenzoate (1) with 3-bromo4-hydroxy-5-methoxybenzaldehyde in the presence of three equivalence of $\mathrm{Na}_{2} \mathrm{~S}_{2} \mathrm{O}_{4}$ in DMSO at $90^{\circ} \mathrm{C} .{ }^{18}$ Base hydrolysis of the compound 2 yielded the title compound (3). The synthesis of ethyl 4-(methylamino)-3-nitrobenzoate (1) was explained in our earlier report. ${ }^{19}$<smiles>CCOC(=O)c1ccc(NC)c([N+](=O)[O-])c1</smiles>

(2)<smiles>CCCC#CCN1c2cc(C(=O)O)ccc2N(C)C1c1cc(Br)c(O)c(OC)c1</smiles>

(3)

Figure I Synthesis of 2-(3-bromo-4-hydroxy-5-methoxyphenyl)-I-methylIH-benzo[d]imidazole-5-carboxylic acid. Reagents: (i) 3-bromo-4-hydroxy-5methoxybenzaldehyde, $\mathrm{Na}_{2} \mathrm{~S}_{2} \mathrm{O}_{4}$, DMSO, stir, reflux at $90^{\circ} \mathrm{C}$ (ii) $\mathrm{EtOH}, \mathrm{NaOH}$ (33\%), and reflux.

Formation of the target molecule was confirmed by the IR (ATR) data. A broad band near $3394 \mathrm{~cm}^{-1}$ justified the presence of $-\mathrm{OH}$ group. A characteristic stretching for acid carbonyl was observed at $1701 \mathrm{~cm}^{-}$ 1. Further, the stretching frequencies for the aromatic and aliphatic hydrogen were observed at 3065, 2906 and $2870 \mathrm{~cm}^{-1}$, respectively. An absorption band at $1624 \mathrm{~cm}^{-1}$ is corresponding to the functional group $\mathrm{C}=\mathrm{N}$ and a sharp band near $525 \mathrm{~cm}^{-1}$ confirms the presence of a bromine atom in the molecule (Supplementary Figure 1).

The ${ }^{1} \mathrm{H}$ NMR spectrum also evidenced the formation of the title compound. A characteristic singlet at $\delta 3.88 \mathrm{ppm}$ was assigned to the three protons of the methoxy group. A peak at $\delta 3.91 \mathrm{ppm}$ is ascribed to the $-N$-methyl protons. Additionally, the spectrum exhibited a doublet for $\mathrm{C}_{2}-\mathrm{H}$ of $3-\mathrm{Br}-4-\mathrm{OH}-5-\mathrm{OMe}-\mathrm{C}_{6} \mathrm{H}_{2}$ at $87.40 \mathrm{ppm}(\mathrm{J}=1.6 \mathrm{~Hz})$ and a proton on the $6^{\text {th }}$ carbon of the $3-\mathrm{Br}-4-\mathrm{OH}-5-\mathrm{OMe}-\mathrm{C}_{6} \mathrm{H}_{2}$ ring 
exhibited a doublet at $87.56 \mathrm{ppm}$ with coupling constant $1.6 \mathrm{~Hz}$, due to meta coupling. The protons on the $7^{\text {th }}$ and $4^{\text {th }}$ carbon atom of the benzimidazole ring displayed two doublets at $\delta 7.66(J=8.2 \mathrm{~Hz})$ and $8.21 \mathrm{ppm}(J=1.2 \mathrm{~Hz})$ correspondingly. A doublet of doublet at $\delta 7.89 \mathrm{ppm}(\mathrm{J}=8.8$ and $1.6 \mathrm{~Hz})$ was accredited to the proton on the $6^{\text {th }}$ carbon atom of the benzimidazole ring. A characteristic broad singlet was appeared at $\delta 10.12 \mathrm{ppm}$ for the hydroxyl group on the $4^{\text {th }}$ position of the 3-Br-4-OH-5-OMe- $\mathrm{C}_{6} \mathrm{H}_{2}$ ring. An acid proton has resonated to give a broad singlet at $\delta 12.79 \mathrm{ppm}$ (Supplementary Figure 2).

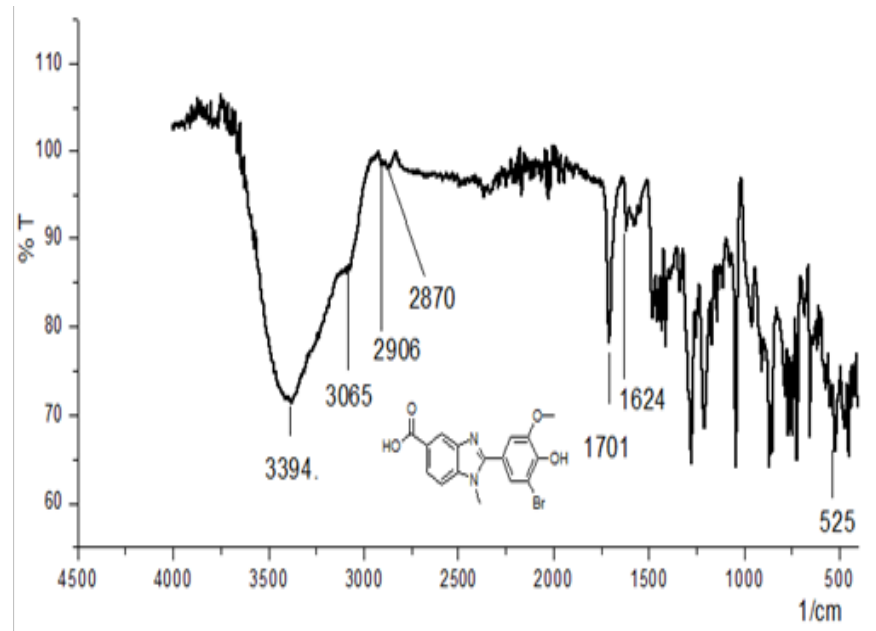

Supplementary Figure I IR spectrum of the compounds 3.

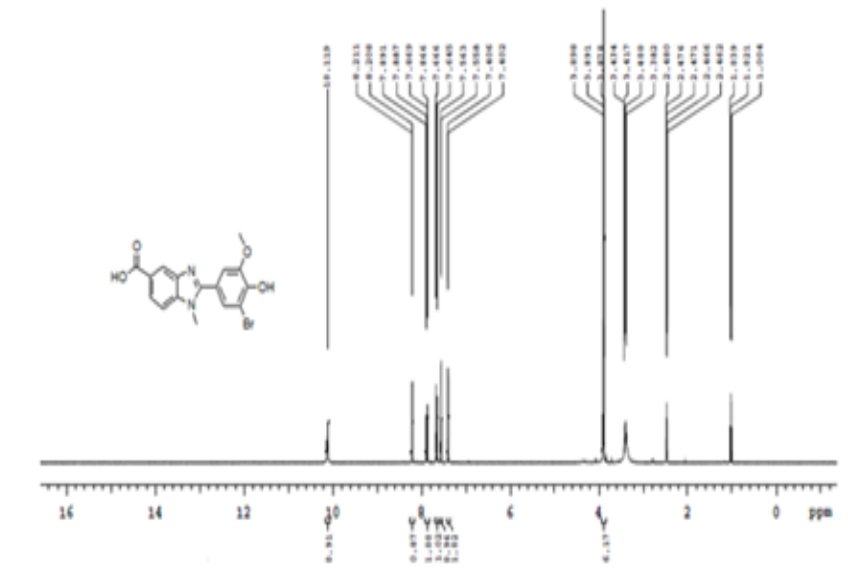

Supplementary Figure 2 'H NMR spectrum of the title compound.

The target molecule is also confirmed by its ${ }^{13} \mathrm{C}$ NMR, which has given a characteristic carbonyl signal at $\delta 168.3 \mathrm{ppm}$. Further, spectrum also exhibited signal at $\delta 154.4 \mathrm{ppm}$, which corresponds to $-\mathrm{C}=\mathrm{N}$ - of the benzimidazole ring. The $4^{\text {th }}$ carbon of the $3-\mathrm{Br}-4-\mathrm{OH}-5-\mathrm{OMe}-\mathrm{C}_{6} \mathrm{H}_{2}$ ring resonated at $\delta 148.7 \mathrm{ppm}$ and the $5^{\text {th }}$ carbon of the same, which is having methoxy substitution, was assigned at $\delta 146.1 \mathrm{ppm}$. The signals at $\delta 142.2$ and $140.1 \mathrm{ppm}$ corresponds to the two $=\mathrm{C}-\mathrm{N}$ - carbon of the benzimidazole ring. The peaks at $\delta 125.8,125.1,124.0,121.8,121.1$, $112.7,111.8,109.7 \mathrm{ppm}$ was assigned for the remaining aromatic carbons. A methoxy and $-\mathrm{N}-\mathrm{CH}_{3}$ carbons were resonated at $\delta 56.9$ and $32.4 \mathrm{ppm}$, respectively. Molecular weight of the compound was in agreement with the data obtained from ESI-MS spectrum with peaks at $(\mathrm{m} / \mathrm{z}) 376.95\left(\mathrm{M}^{+}+\mathrm{H}\right), 378.90\left[\left(\mathrm{M}^{+}+\mathrm{H}\right)+2\right]$. Melting point of the compound was $260^{\circ} \mathrm{C}$ (Supplementary Figure 3).

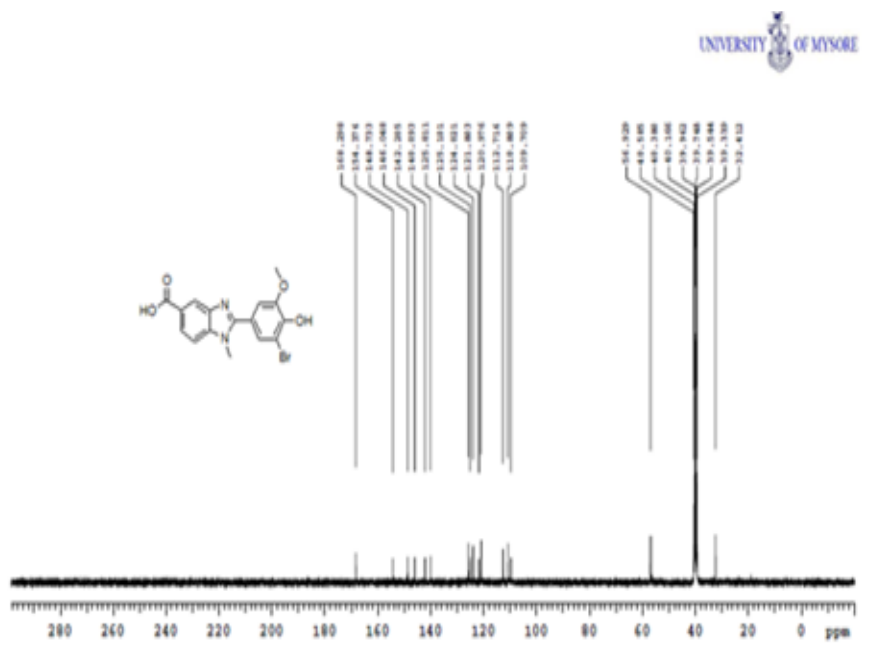

Supplementary Figure $3{ }^{13} \mathrm{C}$ NMR spectrum.

\section{Materials and methods}

Laboratory grade chemicals were procured and desired molecules were synthesized with the aid of standard techniques. Melting point of the target molecule was determined using the open capillary method. The novel synthesized molecules were established and characterized with the help of Thin-layer chromatography (TLC), FTIR spectra were recorded on a Shimadzu ATR Spectrometer, ${ }^{1} \mathrm{H}$ and ${ }^{13} \mathrm{C}$ NMR data from Bruker DRX-300 and 400MHz NMR spectrometer and Bruker DRX-75 and $100 \mathrm{MHz}$ NMR) in (DMSO)- $\mathrm{d}_{6}$, respectively (Tetramethylsilane (TMS-an internal standard)) and ESI-MS spectra by Shimadzu LCMS 2010 spectrometer (Supplementary Figure 4).

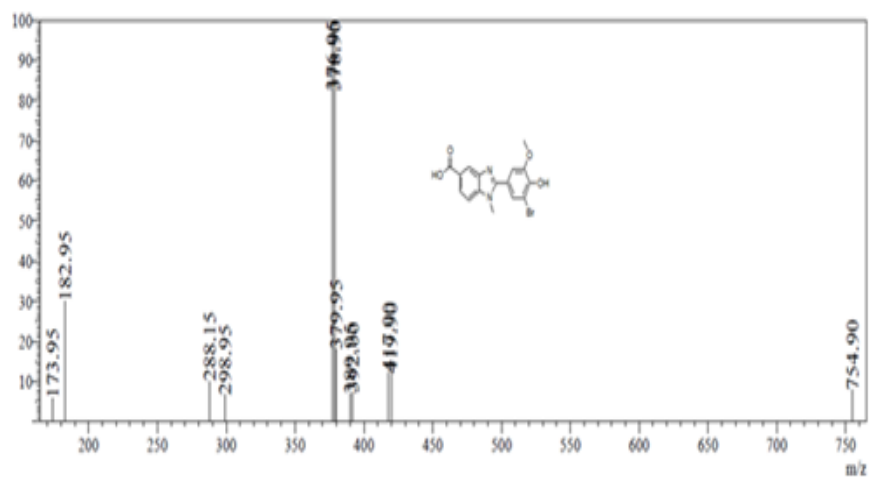

Supplementary Figure 4 ESI-MS Spectrum.

\section{Synthesis of the title compound}

A reaction mixture containing ethyl 4-(methylamino)3-nitrobenzoate (1) $\quad(0.006 \mathrm{~mol}), \quad 3$-bromo-4-hydroxy-5methoxybenzaldehyde $(0.006 \mathrm{~mol})$, sodium dithionate $(0.024 \mathrm{~mol})$ in DMSO was refluxed with stirring at $90^{\circ} \mathrm{C}$ for $3 \mathrm{~h}$. The completion of reaction was monitored by Thin Layer Chromatography (TLC). After completion, the reaction mass was cool to room temperature and poured on crushed ice. The solid formed was collected, filtered and dried, which afforded the compound (2). The hydrolysis of compound (2) with $15 \mathrm{~mL}(33 \%) \mathrm{NaOH}$ in ethanol yielded the required molecule (3) (Figure 2). 


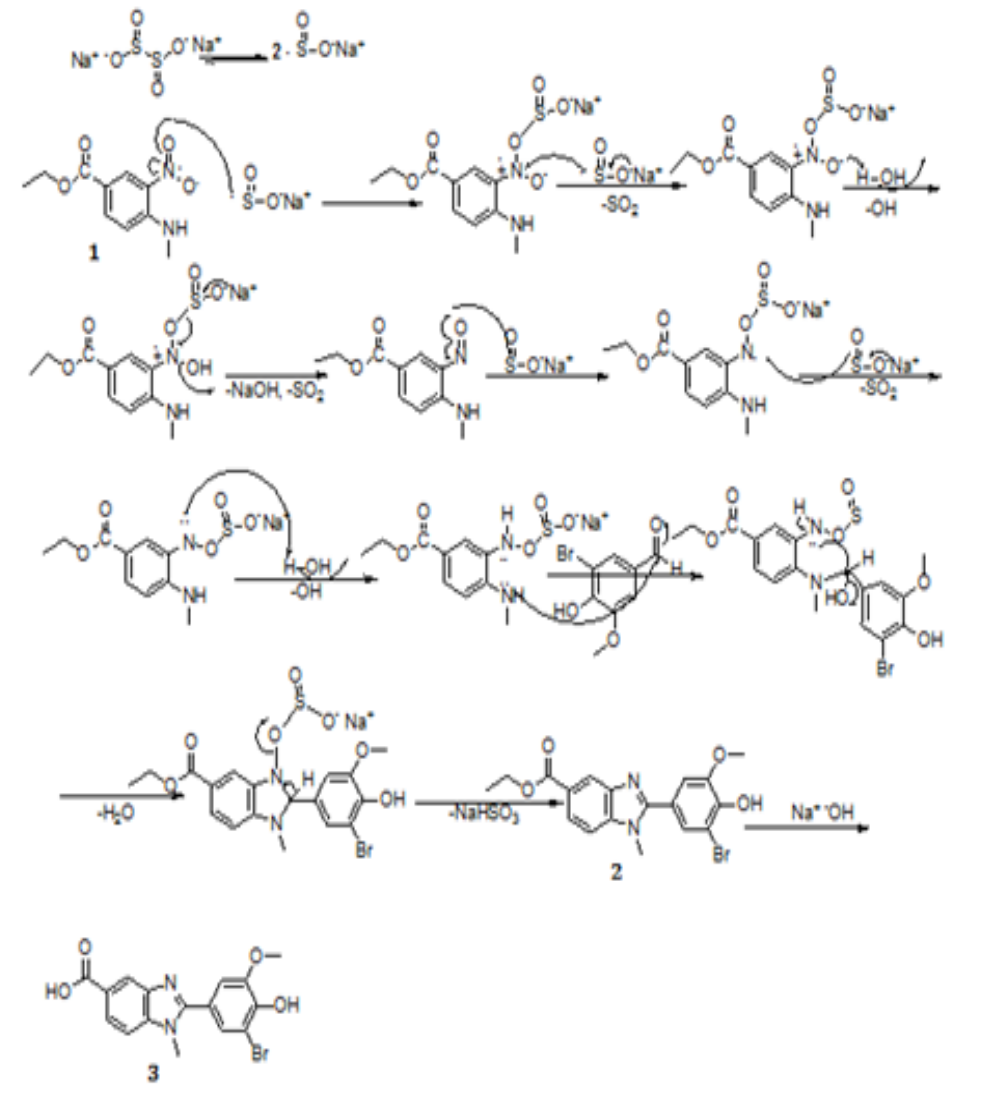

Figure 2 Plausible mechanism for the synthesis of title compound.

\section{Conclusion}

In this present research, a novel benzimidazole acid was easily synthesized with the help of "one-pot" method, followed by the base hydrolysis. The compound under interest was characterized and confirmed with the help of analytical and spectral techniques.

\section{Acknowledgements}

The authors are thankful to the director, Mysore University for providing the NMR data. Authors are also thankful to Mangalore University for rendering the facilities for the research.

\section{Conflict of interest}

All the authors declare that they have no Conflict of interest.

\section{References}

1. Terzioglu N, Gürsoy A. Synthesis and anticancer evaluation of some new hydrazone derivatives of 2, 6-dimethylimidazo [2,1-b]-[1,3,4] thiadiazole-5-carbohydrazide. Eur J Med Chem. 2003;38(7-8):781-786.

2. Gadad AK, Noolvi MN, Karpoormath RV. Synthesis and anti-tubercular activity of a series of 2-sulfonamido/trifluoromethyl-6-substituted imidazo-[2, 1-b]-1, 3, 4-thiadiazole derivatives. Bioorg Med Chem. 2004;12(21):5651-5659.

3. Achar KCS, Hosamani KM, Harisha RS. In-vivo analgesic and anti-inflammatory activities of newly synthesized benzimidazole derivatives. Eur J Med Chem. 2010;45(5):2048-2054.

4. Reddy TS, Kulhari H, Reddy VG, et al. Design, synthesis and biological evaluation of 1,3-diphenyl-1H-pyrazole derivatives containing benzimidazole skeleton as potential anticancer and apoptosis inducing agents. Eur J Med Chem. 2015;101:790-805.
5. El Rashedy AA, Aboul-Enein HY. Benzimidazole Derivatives as Potential Anticancer Agents. Mini Rev Med Chem. 2013;13(3):399-407.

6. Kumar V, Basavarajaswamy G, Rai MV, et al. Rapid 'one-pot' synthesis of a novel benzimidazole-5-carboxylate and its hydrazone derivatives as potential anti-inflammatory and antimicrobial agents. Bioorg Med Chem Lett. 2015;25(7):1420-1426.

7. Zhang D, Wang Z, Xu W, et al. Design, synthesis and antibacterial activity of novel actinonin derivatives containing benzimidazole heterocycles. Eur J Med Chem. 2009;44(5):2202-2210.

8. Refaat HM. Synthesis and anticancer activity of some novel 2-substituted benzimidazole derivatives. Eur J Med Chem. 2010;45(7):29492956.

9. Gaba M, Mohan C. Design, Synthesis and Biological Evaluation of Novel 1,2,5-Substituted Benzimidazole Derivatives as Gastroprotective Anti-inflammatory and Analgesic Agents. Med chem. 2015;5:58-63.

10. Tomei L, Altamura S, Bartholomew L, et al. Mechanism of Action and Antiviral Activity of Benzimidazole-Based Allosteric Inhibitors of the Hepatitis C Virus RNA-Dependent RNA Polymerase. $J$ Virol. 2003;77(24):13225-13231.

11. Jain P, Sharma PK, Rajak H, et al. Design, Synthesis and Biological Evaluation of Some Novel Benzimidazole Derivatives for Their Potential Anticonvulsant Activity. Arch Pharm Res. 2010;33(7):971-980.

12. Zawawi NK, Taha M, Ahmat N, et al. Benzimidazole Derivatives as New $\alpha$-Glucosidase Inhibitors and In Silico Studies. Bioorg Chem. 2015;64:29-36.

13. Paramashivappa R, Kumar PP, Rao PVS, et al. Design, Synthesis and Biological Evaluation of Benzimidazole/Benzothiazole and Benzoxazole Derivatives as Cyclooxygenase Inhibitors. Bioorg Med Chem Lett. 2003;13(4):657-660. 
14. White AW, Almassy R, Calvert AH, et al. Resistance-Modifying Agents. 9. ${ }^{1}$ Synthesis and Biological Properties of Benzimidazole Inhibitors of the DNA Repair Enzyme Poly (ADP-ribose) Polymerase. J Med Chem. 2000;43(22):4084-4097.

15. Gong B, Hong F, Kohm C, et al. Synthesis and SAR of 2-arylbenzoxazoles, benzothiazoles and benzimidazoles as inhibitors of lysophosphatidic acid acyltransferase- $\boldsymbol{\beta}$. Bioorg Med Chem Lett. 2004;14(6):1455-1459.

16. Zhang S, Wang X, He Y, et al. ${ }^{18} \mathrm{~F}$ Labeled benzimidazole derivatives as potential radiotracer for positron emission tomography (PET) tumor imaging. Bioorg Med Chem. 2010;18(7):2394-2401.

17. Shingalapur RV, Hosamani MK, Keri RS, et al. Derivatives of benzimidazole pharmacophore: Synthesis, anticonvulsant, antidiabetic and DNA cleavage studies. Eur J Med Chem. 2010;45(5):1753-1759.

18. Kumar V, Poojary B, Prathibha A, et al. Synthesis of some novel 1,2disubstituted benzimidazole-5-carboxylates via one-pot method using sodium dithionite and its effect on N-debenzylation. Synth Commun 2014;44(23):3414-3425.

19. Shruthi N, Poojary B, Kumar V, et al. Novel benzimidazole-oxadiazole hybrid molecules as promising antimicrobial agents. RSC Advs. 2016;6(10):8303-8316.

20. Preston PN, Weissberger A, Taylor EC. Chemistry of Heterocyclic Compounds. USA: John Wiley and Sons; 1981. 40:6-60.
21. Inamdar SM, More VK, Mandal SK. CuO nano-particles supported on silica, a new catalyst for facile synthesis of benzimidazoles, benzothiazoles and benzoxazoles. Tetrahedron Lett. 2013;54(6):579-583.

22. Tandon VK, Kumar M. $\mathrm{BF}_{3}-\mathrm{Et}_{2} \mathrm{O}$ promoted one-pot expeditious and convenient synthesis of 2-substituted benzimidazoles and 3, 1, 5-benzoxadiazepines. Tetrahedron Lett. 2004;45(21):4185-4187.

23. Tempest P, Ma V, Thomas S, et al. Two-step solution-phase synthesis of novel benzimidazoles utilizing a UDC (Ugi/de-Boc/cyclize) strategy. Tetrahedron Lett. 2001;42(30):4959-4962.

25. Zhoua B, Lib B, Yi W, et al. Synthesis, antioxidant, and antimicrobial evaluation of some 2-arylbenzimidazole derivatives. Bioorg Med Chem Lett. 2013;23(13):3759-3763.

26. Kumar V, Basavarajaswamy G, Rai MV, et al. Rapid 'one-pot' synthesis of a novel benzimidazole-5-carboxylate and its hydrazone derivatives as potential anti-inflammatory and antimicrobial agents. Bioorg Med Chem Lett. 2015;25:1420-1426.

27. Yang D, Fokas D, Li J, et al. A versatile method for the synthesis of benzimidazoles from o-nitroanilines and aldehydes in one step via a reductive cyclization. Synthesis. 2005:47-56.

28. Liu Z, Li HH, Zhao QJ, et al. A facile one-pot synthesis of benzimidazoles from 2-nitroanilines by reductive cyclization. Heterocycles. 2008;75(8):1907-1911. 